appreciation of many of the basic problems of psychiatry. This is now the major benefit to be gained from reading Jaspers as a trainee.

Conrad, K. (1952) Die Gestaltanalyse in der Psychiatrie. Studium Generale, 5, 503-514. English translation (1974) Gestalt analysis in Psychiatry. In Themes and Variations in European Psychiatry. An Anthology. (eds S. R. Hirsch \& M. Shepherd). Bristol: John Wright \& Sons.

- (1958) Die beginnende Schizophrenie. Versuch einer Gestaltsanalyse des Wahns. Stuttgart, New York: Thieme.

DevereuX, G. (1978) Ethnopsychoanalysis. Psychoanalysis and Anthropology as Complementary Frames of Reference. Berkeley, Los Angeles, London: University of California Press.

HABERMAS, J. (1968) Erkenntnis und Interesse. Frankfurt/Main. English translation (by J. J. Shapiro, 1972). Knowledge and Human Interests. London: Heinemann.

Vycotsky, L. S. (1978) Mind in Society. The Development of Higher Psychological Processes (ods M. Cole, V. John-Steiner, S. Scribner, et al). Cambridge, London: Harvard University Press.

Michael Langenbach

Alan S. LeE

Department of Psychiatry

University Hospital

Queen's Medical Centre

Nottingham NG7 2UH

\section{Systemic family therapy}

SIR: We were pleased to read Bloch et als account of the use of systemic family therapy in adult psychiatry (Journal, September 1991, 159, 357-364) and would agree with many of their comments about our limited knowledge of the role of family therapy in adult clinical work.

We are members of a multi-disciplinary group of staff who have been using family therapy within an Old Age Psychiatry service for a similar time. The development of our clinic has been described elsewhere by team members (Marriott \& Pickles, 1987; Benbow, 1988) and we have recently been reviewing our own experience in working with later life families. We have found that the clinic can be helpful with complex and relatively longstanding problems in late life. We have also been experimenting with a team consensus rating, similar to that used by Bloch and co-workers, although we have reservations about using a team rating as an outcome indicator. It is good to hear about others struggling with the same problems.

Our family therapy clinic is, however, not part of a psychotherapy service, but is relatively unusual in that it is integrated within a comprehensive psychogeriatric service. This has problems and advantages (Benbow et al, 1990). We feel that later life is a stage of adulthood when the role of the family is both very important and often neglected. Those who work with the elderly physically and/or mentally ill cannot avoid family problems, but may not often address them. We are aware of an upsurge of interest in this area over recent years.

The issue of cost-effectiveness is a difficult one. Although working in a formal clinic setting in a team is undoubtedly staff-intensive, we feel that experience in family work has spin-offs throughout the elderly service and affects the work of team and non-team members in many spheres. This is difficult (if not impossible) to quantify, but may be an important and little-recognised advantage of staff gaining experience in family therapy. As confidence grows, team members see families outside the clinic, alone or with non-team colleagues. Individuals may 'internalise' the team, enabling team members working alone to utilise interventions and strategies which at one time would not have been available in their repertoires. Work patterns with other agencies are also affected, as well as work with individuals and families outside the clinic.

In Old Age Psychiatry, family therapy adds a new dimension: we feel that we are not what we were!

Benbow, S. M. (1988) Family therapy in the elderly. In Current Approaches in Affective Disorders in the Elderly (eds E. Murphy \& S. W. Parker). Southampton: Duphar Laboratories Ltd.

- EgAN, D., MARRIOTt, A. et al (1990) Using the family life cycle with later life families. Journal of Family Therapy, 12, 321-340.

MARRIOTt, A. \& PICKLES, A. (1987) A family clinic for the elderly in central Manchester. PSIGE, 24 (Oct), 12-14.

S. M. BENBOW

A. MARRIOTT

G. DAwSON

York House

Manchester Royal Infirmary

Oxford Road

Manchester

M139BX

\section{Polycythaemia and psychotic depression}

SiR: Murray \& Hodgson (Journal, June 1991, 158, 842-844) have described the first case of polycythaemia rubra vera complicated by psychotic depression. We describe here a second case of psychotic depression associated with polycythaemia rubra vera.

Case report. A, a 69-year-old woman with no family or personal history of psychiatric disorders, was found to have polycythaemia rubra vera (RBC 9.9 million $/ \mathrm{mm}^{3}$; WBC $16000 / \mathrm{mm}^{3}$; platelets $1.4 \mathrm{million} / \mathrm{mm}^{3}$; splenomegaly) when she was 49 , in 1971, during investigations for an acute myocardial infarction. During the following seven years she had another myocardial infarction, frequent transient 
ischaemic attacks and, finally, in 1977, a stroke with a right hemiparesis which disappeared in a month. Three years later, in 1980, nine years after the diagnosis of polycythaemia rubra vera, she had her first depressive episode, with dysphoria, suicidal ideation, psychomotor retardation, persecutory delusions, loss of interest, weight loss, and anergia. No significant life events preceded its onset. Depression ran a chronic fluctuating course, with transient periods of improvement, until she was visited by us, in 1991, still depressed and paranoid. She had $9.9 \mathrm{million} / \mathrm{mm}^{3} \mathrm{RBCs}$, $14000 / \mathrm{mm}^{3}$ WBCs and $900000 / \mathrm{mm}^{3}$ platelets. She had been treated with different antidepressant, antipsychotic and antianxiety drugs. During the last two years polycythaemia had been treated with busulfan (an alkylating agent) and pentoxifylline, which did not change the course of her depression. Previously, she had been treated with aspirin.

Although depression is a well known complication of stroke, the appearance of depression in our case three years later, and its course, point against a causal relationship. Her depression appeared nine years after the diagnosis of polycythaemia and this points against a 'reactive' depression. Clearly, it is possible that the association between polycythaemia and psychotic depression in our case was casual; however, depression seems to be a not uncommon complication of polycythaemia rubra vera, according to the haematology literature cited by Murray \& Hodgson.

Marco Mazzoli

Psychiatry Service

Public Hospital 'Morgagni'

47100 Forli

Italy

via Pozzetto 17

48010 Castiglione de Cervia RA

Italy

\section{Phobic disorders and benzodiazepines in the elderly}

SIR: In his interesting paper Lindesay (Journal, October 1991, 159, 531-541) fails to consider the possibility that benzodiazepine drugs may have been the cause of the late-onset phobias in some of his patients. In 11 of 18 in whom the main fear began after the age of 65 years, it followed a physical event, and in five, some other traumatic exposure such as a mugging, a fall or being trapped in a lift. In all these situations it is not unusual (although of course wrong) for benzodiazepine drugs to be given, and not infrequently they continue to be given subsequently. Nineteen of Dr Lindesay's cases were taking psychotropic medication, most commonly a benzodiazepine, but we do not know from his data what the relationship of taking these drugs was to the onset or aggravation of the symptoms.
The natural history of anxiety symptoms following illnesses or trauma is towards natural resolution and when this does not happen one must always consider what may be keeping them going. In some patients, perhaps because of their individual vulnerability, the cause is benzodiazepine drugs and if this is the case these patients can be totally relieved of their symptoms. This problem arises at all ages and is illustrated by the following example in an elderly patient.

Case report. A lady of 75 had always been rather phobic of lifts and of trains but for two years she had suffered from severe anxiety, panic, terror and misery. This followed an operation on her knee, since when she had taken lorazepam $2 \mathrm{mg}$ daily. She was so frightened that when travelling in the car with her husband she felt she wanted to jump out of the car if he stopped at traffic lights, and a measure of the intensity of this feeling was that her husband fixed a special lock on the door. She could not be left alone in the car while he went into a shop to buy a newspaper. Her tablets were stopped over a period of four weeks with suitable explanation of what to expect by way of withdrawal symptoms, and at the end of five weeks she said it had been "the worst five weeks of my life". At eight weeks there had been a few spells of feeling normal and at 12 weeks she had been in a lift although severe insomnia persisted. At 16 weeks she was completely well, happy and free of symptoms. She could sit in the car long enough for her husband to have his hair cut.

This is not a new idea. Ashton (1984) pointed out that many patients develop phobias for the first time after a period of regular benzodiazepine use and that these symptoms disappear when the drug is withdrawn. Her paper gives references to a similar view expressed previously by Lader, Tyrer and others. The above example is one among many such patients, of all ages, and although it is not always easy to wean patients from their tablets it can usually be done with appropriate support and explanation and these patients become some of the most grateful a psychiatrist can have.

AsHTon, H. (1984) Benzodiazepine withdrawal: an unfinished story. British Medical Journal. 288, 1135-1140.

The London Hospital Medical College

SAmuel I. COHEN Turner Street

London EI $2 A D$

\section{NMS complicated by diazepam}

SIR: Neuroleptic agents are used extensively in psychogeriatric practice, including the management of behavioural problems in Alzheimer's disease. Serby (1986) reported NMS in a patient with Alzheimer's disease. Finucane et al (1984) reported NMS in an 81-year-old man, induced by haloperidol. This communication pertains to a 67-year-old gentleman who 